Portland State University

PDXScholar

$5-24-2019$

\title{
An Equitable Approach to Addressing Mental Illness Within U.S. Study Abroad Programs
}

Katie J. Clark

Portland State University

Follow this and additional works at: https://pdxscholar.library.pdx.edu/honorstheses

Let us know how access to this document benefits you.

\section{Recommended Citation}

Clark, Katie J., "An Equitable Approach to Addressing Mental Illness Within U.S. Study Abroad Programs" (2019). University Honors Theses. Paper 709.

https://doi.org/10.15760/honors.726

This Thesis is brought to you for free and open access. It has been accepted for inclusion in University Honors Theses by an authorized administrator of PDXScholar. Please contact us if we can make this document more accessible: pdxscholar@pdx.edu. 
An Equitable Approach to Addressing Mental Illness Within U.S. Study Abroad Programs

By

Katie J. Clark

An undergraduate honors thesis submitted in partial fulfillment of the

Requirements for the degree of

Bachelor of Arts

in

University Honors

And

Social Work

Thesis Adviser

Karen Moorhead, LMSW

Portland State University

2019 
An Equitable Approach to Addressing Mental Illness Within U.S. Study Abroad Programs

\begin{abstract}
Research within the field of study abroad with a focus on college students within the United States with a mental illness has shown a need for an inclusive and equitable approach to the mental health screening and incorporating a collaborative process between the student, faculty leading the Short-Term Faculty-Led program and resource centers. This paper has incorporated findings as well as identified areas of improvements and new collaborative and trauma informed approaches that can be incorporated into study abroad programs. This entails students being informed of their rights to privacy, explanation of the process before self disclosure of their mental illness and/or symptoms; collaboration with resource centers on campus, and providing students the choice to collaborate with providers to create a care plan and create accommodations to implement while abroad. The importance of this research is to provide a rich cultural and educational study abroad experience and best support students with a mental illness studying abroad.
\end{abstract}

\title{
Introduction
}

Study abroad programs in colleges and universities across the United States are well sought after, there are many factors that propel students to study abroad in a foreign country. Students are in search of expanding their cultural knowledge, gaining new experiences, and viewing the world through a different lens. Study abroad programs within the U.S. provide differing experiences, ranging in duration, distance, cost, and facilitators who lead the study abroad program. The student applicant can choose from: Short-term Faculty-led Programs, Fully Integrated Programs at Foreign Universities, Island Programs for U.S. Students, or Hybrid Programs (PSU Education Abroad, 2019). The study abroad program of focus within this paper 
An Equitable Approach to Addressing Mental Illness Within U.S. Study Abroad Programs

is the Short-term Faculty-led programs, and specifically addressing barriers to students receiving accommodations for their mental illness within the pre-admission section of the Short-term Faculty-Led study abroad Program. There are opportunities for Short-term Faculty-led study abroad programs to create an inclusive approach to the mental health screening that are equitable and promote self determination (decide what is in their own best interest) of the student with a mental illness while in the pre-departure phase of preparations for the study abroad experience (Paras, Carignan, Brenner, Hardy, Malmgren, \& Rathburn, 2019).

College students in the U.S. can benefit in various aspects of their life from studying abroad, study abroad students have the unique ability to experience a different culture, perhaps acquire a new language, and gain world knowledge. All of the wonderful benefits gained from the study abroad experience are appealing, however, there are systemic barriers that create a plethora of deterrents for U.S. college students with a mental illness. U.S. college students applying for a study abroad program are confronted with a challenging decision, whether or not they should self-disclose their mental illness in the pre-admission phase of the study abroad program. There is a possibility that after a college student self-discloses their mental illness within the pre-admission application stage they could potentially be disqualified from participating in the study abroad program.

Study abroad offices incorporating an inclusive and equitable approach, consists of a collaboration post-admission into the study abroad short-term Faculty-Led program with a selfdisclosed student with a mental illness. The collaboration includes resource centers (Disability Resource Center (DRC) \& Student Health and Counseling (SHAC)) study abroad office, and the self-identified student with a mental illness. Through collaboration with the student and 
An Equitable Approach to Addressing Mental Illness Within U.S. Study Abroad Programs

stakeholders, all can assist in formulating a care plan, and establishment of accommodations. The collaboration process with all stakeholders and establishment of accommodations post-admission of the student provides an equitable approach to addressing mental illness within study abroad programs; and stands to provide the student the autonomy to assist in their own care plan and state accommodations needed without fear of termination of their application. The contributions made will assist study abroad programs structuring a health questionnaire that will include a release of information form regarding the students rights and how FERPA, HIPAA, \& ADA apply to the student disclosing their mental illness or symptoms. The explanation of legal protections in place will lessen the stigma that inhibits students from disclosing their mental illness or symptoms, and students can make an informed decision about self-disclosing.

The self-disclosing student's health questionnaire can be analyzed by a DRC counselor (ADA compliant staff member) and a follow-up with the student regarding accommodations while abroad. "In regards to disability-related inquiries, some institutions may prefer to have the disability services office handle all disability-related inquiries on behalf of the study abroad office"(Choi, Venetis, Greene, Magsamen-Conrad,Checton \& Banerjee, 2016). There can be a collaboration between the student (self-discloser), DRC, SHAC, and the faculty member leading the short-term study abroad. The DRC can provide an avenue which allows for grievances to be filed, addressed, and reviewed by an equity committee. A grievance process can provide accountability to all stakeholders this includes faculty members, study abroad advisors, on-site program faculty and staff.This promotes inclusion and an equitable approach to the application process to limit discriminatory acts. 
An Equitable Approach to Addressing Mental Illness Within U.S. Study Abroad Programs

\section{Confidentiality and Student's Rights}

Study abroad programs can become more inclusive and equitable in the mental health screening portion within the health questionnaire. The mental health segment of the health questionnaire causes stress on applicants especially if the mental health screening is required to be filled out and submitted before the applicant is accepted into the study abroad program.To limit stress and protect students privacy regarding their mental health, there is a need to inform students of pertinent information; regarding protection of the students rights, their confidential information, and how these various protection measures are applicable to the student applicant.

There are applicable legal protections to share with students such as the Americans with Disabilities Act (ADA), The Family Educational Rights and Privacy Act (FERPA), Health Insurance Portability and Accountability Act (HIPAA). Incorporating a Release of Information (ROI) informing students their various legal protections (ADA, FERPA, HIPAA) pre-disclosure can create an opportunity for safer disclosure. Explanation of these various security measures can be included in the ROI, how it pertains to the student, their confidential information and a possible self-disclosure of a mental illness (Morse, Spoltore \& Galvinhill, 2017).

Before filling out the health questionnaire and disclosure of information, students can benefit from reading through these materials ADA, FERPA, HIPAA, and their options for resources. Then sign an ROI which should entail the rights of the student and address what is included in ADA, HIPAA and FERPA as well as what is not covered and any legal protections a student may have. These measures are used to inform the student of their ability to advocate for themselves, and understand their power to file a grievance if they are treated unfairly or discriminated against for their disclosure. 
An Equitable Approach to Addressing Mental Illness Within U.S. Study Abroad Programs

Students should be enlisted into this process, deciding for themselves what supports they need to put in place in the pre-departure stage, discuss what accommodations can be in place so if they're in need of support that this has been planned, and can be implemented in accordance to the agreed upon strategy."We strongly recommend engaging with study away professionals, both on campus and third party providers, to provide advocacy, support, education, and crisis consultation" ( Morse, Spoltore \& Galvinhill, 2017).

Starting the collaboration process with resource services on campus, there should be a Release of Information signed by the student to allow discussion and collaboration to take place regarding the student's care. The collaboration amongst professionals will only entail accommodations, and sensitive medical/mental health information if applicable."It is important to inform clients that when they request to have us release confidential information to other parties on campus, this released information becomes part of the educational record and is subject to other guidelines such as The Family Educational Rights and Privacy Act (FERPA)" (Morse, Spoltore \& Galvinhill, 2017).

\section{Ethical Approach}

Inclusivity and an ethical approach to inclusion of the student applicant going through the study abroad process includes informing students of their rights, what the next steps will entail after they've been approved and accepted into the study abroad program. Once they've been granted entrance to the next phase, they must complete their health questionnaire, this is difficult for students to fill out. Self disclosing any medical or mental health information could potentially be used against them in the decision making process, this fear can inhibit a student from self disclosing and potentially missing an opportunity for professionals both in the study abroad 
An Equitable Approach to Addressing Mental Illness Within U.S. Study Abroad Programs

program and on campus supports to assist the student in the pre-departure phase, and during the study abroad experience.

The actions that can be taken such as creating an inclusive form describing best ethical practices taken by the study abroad office in regards to students disclosed information can show that there is value and confidentiality taken to ensure students feel included, accommodated, and open. Informing study abroad student applicants that the disclosure and participation in the process will not disqualify the student from participating, disclosing will be confidential, and which professionals will have access to their medical/educational record. "Fully educating a student about the process involved with studying away can potentially avoid surprises and help to empower the student to make informed decisions"( Morse, Spoltore \& Galvinhill, 2017). To ensure privacy, requiring the student to sign ROI's with the specific support centers they will utilize to prepare in the pre-departure stage can create a safety net for all stakeholders involved. Students that are informed of resources that may benefit them or a necessary while abroad can impact their engagement in the process and assist them in being proactive about their care. An ethical approach to ensuring all stakeholders adhere to privacy, ethical and inclusive practices, it is necessary to have a formal grievance process for students. The student's right to a formal grievance process should be easily accessible and student's should be informed in the ROI they have the ability to file a grievance. If at any point the student feels they're being treated unjustly or discriminated against, or denied participation in a study abroad program because of their mental illness they have the right to file a grievance.

Exclusion from the program due to the mental health disclosure could potentially violate the laws in place protecting students from discrimination. Students may be utilizing disabled 
An Equitable Approach to Addressing Mental Illness Within U.S. Study Abroad Programs

student resources on campus and are protected by the ADA, which allows for disabled persons rights to be protected, "Section 504 of the Rehabilitation Act ("Section 504") and Titles II and III of the Americans with Disabilities Act ("ADA") and their implementing regulations all apply in the higher education context and prohibit discrimination on the basis of disability against otherwise qualified individuals with disabilities" (Choi, Venetis, Greene, MagsamenConrad,Checton \& Banerjee, 2016).

\section{Self-Disclosure \& Third Party Organizers}

College students applying for a study abroad program in the U.S. are confronted with the difficult decision of self disclosing their mental illness in the early stages of the admission process. "Students are confronted with a difficult decision to self disclose and run the risk of being disqualified from participating in a study abroad program" (Hunley, 2010). The request for student applicants filling out required study abroad health questionnaire are asked to self disclose their mental illness. The requirement to complete the form usually takes place after an initial screening for the study abroad program the student applied for. The study abroad office sends out a health questionnaire that is required by the student applicant to fill out, accessed by the study abroad program and the third party organizers that the study abroad office utilizes abroad. The filled out health questionnaire is usually shared within the domestic on-campus study abroad program and the director/coordinator of the program in the host country.

The faculty member leading the program abroad will be informed of the student's mental illness/and or symptoms, and the third party organizers/company that plan excursions, or other events, will most likely have access to the students health questionnaire. There isn't a need for investigating into their past mental health history or diagnosis as this can become a deterrent to 
An Equitable Approach to Addressing Mental Illness Within U.S. Study Abroad Programs

disclosing their mental illness for fear of being excluded from the study abroad experience.

"Detailed questions about dates of mental health counseling, medications and dosages, diagnoses, hospitalizations, and history of suicidal behaviors have no place in an application for a study away program"(Morse, Spoltore \& Galvinhill, 2017). The idea of self disclosure of the student's mental illness is to receive support for the symptoms they may present while abroad, enlisting the assistance of the faculty member leading the study abroad experience. This assists the student in receiving accommodations through the collaborative team approach that occurs when the study abroad office follows up with the student.

Disclosing personal information such as mental health diagnosis is not necessary, nor is it a necessity for study abroad programs to attain previous mental health treatment. "People who plan to disclose personally stigmatized information will engage in complicated cost and benefit analysis, deliberating their capabilities to disclose information, and potential social rejection" (Feldman \& Crandall, 2007; Greene, 2009; Ragins, 2008). The reasoning for students to disclose their mental illness or their symptoms, is to obtain support through accommodations while abroad because they are away from their support system, culture shock is occuring, and that's usually when symptoms show during these times of stress.

An inclusive and equitable approach would be to inquire of the student what kind of accommodations are necessary for them to be successful before and during the study abroad experience.“'Once students have been admitted to a study abroad program, study abroad administrators may make confidential inquiries or provide information of the contact person for the Disability Resource Center for the admitted students to determine whether they may need accommodations during the program. These confidential inquiries may be related to both mental 
An Equitable Approach to Addressing Mental Illness Within U.S. Study Abroad Programs

and physical disabilities" (Choi, Venetis, Greene, Magsamen-Conrad,Checton \& Banerjee, 2016). Connecting the student with the DRC can provide an equitable approach to supporting and accommodating through study abroad pre-departure phase to best prepare for the abroad experience. The DRC can collaborate with the student by inquiring of the asking the student what symptoms look like and what kind of accommodation or approach the faculty leading the study abroad should be aware of and plan around that.

\section{Collaborative Care}

There is an establishment of care team with providers as well as resource centers such as (Student Health and Counseling (SHAC), Disability Resource Center (DRC), and more) on campus that may be utilized for putting supports in place and collaborating with the student to create a care plan for the study abroad trip. There is only a need for current information pertaining to the student's mental illness/and or symptoms and not previous or past treatment history. The approach to disclosure is enlisting the DRC counselor (with permission from the student) to discuss accommodations needed pertaining to the study abroad experience, what information can be disclosed with stakeholders; how staff or faculty member implement accommodations to support the student abroad, and putting a care plan in place so the student is best prepared for the trip if symptoms were to arise.

Students are asked to disclose personal information regarding any mental illness diagnoses, previous treatment for their diagnosis, including any hospitalizations, medications, suicide attempts, and treatment received for their mental illness. "Students may view the assessment as a potential barrier to attending the program of their choice, and if they self disclose they could be excluded from participating in the study abroad experience, therefore may not 
An Equitable Approach to Addressing Mental Illness Within U.S. Study Abroad Programs

disclose their mental illness on the form” (Morse, Spoltore \& Galvinhill, 2017, p. 332). The study abroad program on the University's campus can address the barriers that students with mental illnesses face, by creating a health questionnaire that is inclusive, empowering and ADA conscious. This entails informing students of their rights, laying out what questions the students are required to answer, what can be expected when the student discloses their mental illness diagnoses/symptoms. Informing students of their right, is an equitable approach that can be taken instead of disclosing diagnosis, and other unnecessary treatment history instead focus on what accommodations are needed; what the faculty member can provide the student and supports to be put in place pre-departure and while abroad.

The study abroad program must have full disclosure and transparency with the student disclosing their mental illness, and provide a release of information portion prior to the student completing the mental health questionnaire. "It is crucial to be open with students about what information will be requested and when that information will be required. If there are standard release forms that students will be asked to complete, it is helpful to make these available to students prior to their applying"(Morse, Spoltore \& Galvinhill, 2017). The disclosure form must consist of an explanation of how the student's mental illness diagnosis will be protected within the University's system. Transparency of who within and outside of the institution has access to their mental health information, duration of time the information is accessible and what are the students rights in revoking the access to their mental health information. Students need to have full disclosure and transparency of potential threats to their confidential disclosures within their mental health questionnaire, in addition to full transparency of access to the student's confidential information. Students need to be informed whether their disclosure will be included 
An Equitable Approach to Addressing Mental Illness Within U.S. Study Abroad Programs

in their academic record, could potential employers or other educational programs have access to this confidential information.

\section{Accommodations}

The student that discloses their mental illness or symptoms can utilize a support team to receive proper accommodations throughout their study abroad pre and during departure stages. The collaborative approach between student and care team consisting of their doctor, medical provider, therapist, resource center such as the DRC, and or SHAC. Students are the experts on themselves, they know what accommodations they may need while studying abroad, having an open dialogue with them about their care plan and needs is pertinent. Addressing the student as the key stakeholder is integral to creating an inclusive and equitable study abroad experience. The collaboration of providers and the student can create open dialogue regarding accommodations and formation of a care plan to be formed then implemented by the student and the faculty member leading the study abroad program.

Collaboration of resource centers and creating open dialogue can limit stigma surrounding mental illness and being forthright with information surrounding the process of disclosure. Transparency of what stakeholders have access to the students records in regards to HIPAA and FERPA, and how the institution protects students confidential information what will happen with the disclosed mental health information. Study abroad programs have an opportunity to create an inclusive and equitable process by faculty/staff informing the student of their rights and the various collaborating stakeholders that have access to their student records.

The approach utilized within the disclosure process could assist students in being informed about going forward and knowing who has access to their health information as well as 
An Equitable Approach to Addressing Mental Illness Within U.S. Study Abroad Programs

their mental health diagnosis or symptoms. The use of an ROI pre-disclosure will remove the unknowns for the student and allow the student to openly participate in the process. They are the experts of themselves, their needs, and student's informed of their rights can feel empowered to engage in their own care planning and collaborate between resource centers, providers, study abroad office, and the faculty leading the study abroad program. Intensive collaboration will best prepare the student for their study abroad experience and create an open, supportive, and fruitful learning experience that the student deserves. The use of collaboration with care providers is going in with the joint goal of setting the student up for success by creating a safety net, accommodations, and point people to reach out to that are already incorporated into the care plan for abroad "Advise students to prepare for their experiences abroad and have workable plans, preferably designed with their treating mental health professionals, before departure to minimize the negative consequences of unexpected events" (Prince, 2019).

The next steps should entail collaborative efforts between study abroad professionals and on campus resource centers such as SHAC. This will allow for direct communication, discuss what the student's accommodations will entail, and if there is medicine or continued treatment needed while abroad. "U.S. education abroad professionals need to collaborate with mental health professionals to determine whether a particular student will need continued treatment and/or medication management while abroad, and how to best support the student's success in the program" (P. Prince, 2019). Collaborating with the student after self disclosure will be most supportive to the student so the student can have autonomy in the process, and voice their needs and concerns about studying abroad with the assistance of accommodations such as treatment, medication management, and support from education abroad professionals. 
An Equitable Approach to Addressing Mental Illness Within U.S. Study Abroad Programs

\section{Accountability \& Grievances}

Students that have had adverse experiences throughout the process will find it beneficial to utilize a grievance process, and receive support surrounding their concerns, and hold professionals and stakeholders accountable in their role. Students should be informed early on in the pre-admission application process of where they can file a grievance, privacy ensured, and what office handles the grievances, this allows more honesty on the part of the student. There is also the ability for students that are denied participation in the study abroad program within the early application and screening process to file a grievance and have a review of their case. The use of grievances assists in accountability from staff, faculty, study abroad programs, and creates safety, and order within institutions. It's beneficial to all stakeholders to have a grievance process in place, to create a more inclusive and equitable approach to addressing mental illness in study abroad programs. Students can benefit from the ability for a third party assessment of their application and concerns and have a review of their grievance, this ensures that there is adherence to the proper policy, procedure, laws, and regulations at multiple levels.

There are numerous benefits to establishing a grievance process for all parties involved, there are clear lines of communication of the process, contact people, department, expectancy of review length, students involvement, and potential outcomes. Grievances can be filed and investigated through: The Office of the Dean of Student Life, Student Health and Counseling Center, TITLE IX office, Disability Resource Center or forming a student grievance committee through the study abroad office. The establishment of the grievance process protects students from discrimination in response to their self disclosure of their mental illness. The establishment 
An Equitable Approach to Addressing Mental Illness Within U.S. Study Abroad Programs

of this avenue can protect the university, by instituting a grievance process, and holding study abroad officials accountable for the screening and admissions process.

There is a great need for a grievance process for students if they feel they were indeed discriminated against, or if they disagree with the admissions decision or recommendation made from a medical provider. The accountability that a grievance process may have with the admission process could potentially allow a fair process for the student, provide students support, to feel open and safe to self disclose their mental illness and/ or symptoms without fear of backlash. "Under FERPA, a university is required by law to protect the privacy of identifiable health information. In most circumstances, medical records should not be released unless there is written consent" (Prince, 2019).

There is accountability when students file grievances if they are being discriminated against, or treated unjustly, and they have the right to receive a review of their application at any point in the process and automatic review after denial of an application. Students can take an active part in their care by collaborating with providers within their chosen care team, and assist in forming accommodations they can implement pre-departure and during the study abroad. This ensures students are apart of the process, and for the study abroad program, those that are representatives of that entity, providers, and the implementing grievances which

Creating a space for students to discuss concerns pre-admission and pre-disclosure can ease their stress and anxiety through the pre-application stages. Through the use of a DRC and/or study abroad advisor can answer questions that pertain to mental health and if the student has concerns whether accommodations can be made and implemented while abroad. Perhaps students are curious if their medication is legal within their host country and will be utilizing the 
An Equitable Approach to Addressing Mental Illness Within U.S. Study Abroad Programs

medication as a needed accommodation. It would be beneficial for the student to feel

comfortable and open by inquiring of the study abroad staff or faculty as some medication is legal and others are not. Discussing medication with the collaboration of resource centers, and providers, can be beneficial as students need to know if they can bring their medication into the country they're applying to.

Study abroad programs would benefit from open and direct dialogue with students regarding mental illness and symptoms. Creating an atmosphere where students feel comfortable and trust the program will likely bring more honesty from the student applicants. If they feel fully informed and have protections in place, thy are more likely to be open and provide more accurate information to faculty and staff. Study abroad professionals and the faculty leading short term study abroad programs can best prepare to support students abroad by collaborating with campus resource centers, collaborate with the student surrounding accommodations needed for pre-departure and during the study abroad experience. Faculty should be prepared to answer questions, collaborate with other university resource centers, maintain confidentiality, and ready to implement what accommodations the student can utilize while abroad. "Mental health information and resources for students studying abroad is lacking. Often, study abroad programs do not have the resources necessary to deal with mental health issues" (Hunley, 2010). Prefacing the mental health screening with a disclosure, including limits of confidentiality, students rights, FERPA, ADA, HIPAA, TITLE IX, grievances process, resource centers to utilize for accommodations (DRC \& SHAC) and fast facts summarizing each of the resources. In addition to advocates available to explain these services, and areas of the health questionnaire that require disclosure and where disclosure of intimate details can be skipped. 
An Equitable Approach to Addressing Mental Illness Within U.S. Study Abroad Programs

\section{Accountability Measures To Be Taken}

The study abroad program can create inclusivity through the enhancement of their established health questionnaire, by adding the disclosure of students rights and protection of their confidential information (HIPAA \& FERPA) as well as inclusion of ADA in the proposed post-admission health questionnaire form utilized in the mental health screening. This is useful for students to be best informed through the use of a disclosure form, informing students of their rights before the disclose their mental illness or symptoms they currently or could experience abroad. Students having access to the disclosure of rights, and ADA information as well as information about collaborative care of resource centers such as (SHAC \& DRC). Access to the disclosure will best inform and empower students to make an informed decision that will impact how their medical information is shared, discussed, who has access, and other legal parameters protecting their confidential mental health screening.

Disclosures of pertinent information regarding a student's mental health, accommodations, and collaboration of care requires (resource centers) protections and policies that cover study abroad programs to assist in ethical and confidential measures taken."Many institutions try to have policies for education abroad programs that mirror campus policies whenever possible" (Prince, 2019). Implementing policies that are similar to the campus wide policies used can assist study abroad programs in retaining and practicing ethical behavior. This concept of collaborative care assists in focus on symptoms the student is/has manifested, their anticipated and current accommodations needed to implement pre-departure and abroad.

The collaboration of students with resource centers on campus is vital to the student success, and including the Short-term Faculty member facilitating the study abroad experience 
An Equitable Approach to Addressing Mental Illness Within U.S. Study Abroad Programs

can enhance and best support the student participant. Utilizing the disclosure of student's rights and the post-admission health questionnaire that contains the mental health screening can benefit students as well as the faculty and staff of the study abroad program. There are less opportunities for personal bias, discrimination, and stigma of mental illness and accommodations due to the fact the admission process is required first before the student has access to the disclosure and mental health screening form. Through inclusive and equitable approaches in the disclosure application portion by ensuring confidentiality with post-admission disclosures, and the protections taken to secure students secure information. As well as the establishment of a grievance process either through a student grievance committee, the DRC, or SHAC, or other third party entity on campus. Study abroad professionals can create an inclusive process and hold accountability while building trust with the student. There is a grievance process students can go through in order to obtain equitable and inclusive treatment throughout their entire application process. The study abroad student applicant can form a grievance for unfair treatment throughout the process/and after a decision.

Accountability is required to assist in an equitable approach amongst professionals handling students applications, confidential information, and accommodations. The collaboration of resource centers, faculty leading the study abroad program, and amongst other stakeholders can create an ethical dilemma through a breach in security. Thus students self-determination is a large factor as they choose what resource centers they will utilize to create accommodations for abroad, and how their information is shared and rights they have if their information is mishandled. The grievance process allows for accountability amongst professionals, as well as 
An Equitable Approach to Addressing Mental Illness Within U.S. Study Abroad Programs

the entire approach taken beginning with the proposed post-admission disclosure and health questionnaire form through the implementation of accommodations abroad.

\section{Recommendations \& Assessing Study Abroad Programs}

Study abroad programs are consistently seeking feedback about their effectiveness as a program, meeting the needs of the students, and improvements to better support a student's study abroad experience. "The field of study abroad is increasingly driven by accountability and interest in student learning to engage with outcomes assessment” (Savicki \& Brewer, 2015). Through the utilization of an informed and collaborative approach to the health questionnaire, and creating a plan of action for the accommodations needed, with implementation while abroad, will impact student success.Creating and distributing a pre-departure, during, and after study abroad survey could benefit not only the study abroad program, the third party organization, but also the student participants. "Embed assessment in ongoing processes, in pre-departure (advising orientation), during (courses, programming), and/or post-study abroad (reflective activities, course work, and capstones)" (Savicki \& Brewer, 2015). Implementing a three part survey can improve the functioning of the new implementations made by the program, notice any trends in the responses, and allow for students personal feedback which allows the student another opportunity to feel included in the process.

Through the use of the three part survey series, the student can add personal feedback about their experience with the disclosure of student rights, the post-admission health questionnaire, and collaborative approach taken and accommodations provided. Student evaluation of the program, application process, collaboration with resource centers or grievance process will beneficial for all stakeholders. Those that benefit from the surveys are the admission 
An Equitable Approach to Addressing Mental Illness Within U.S. Study Abroad Programs

counselors, resource centers, faculty leading the short-term study abroad, the University or college as well as the third party program. The surveys distributed emphasizes feedback in effectiveness of how students medical information was approached, confidentiality, if the support abroad was beneficial, did they use accommodations, were the accommodations supportive, and if they felt included in the collaboration of their care. Evaluation of the shortterm Faculty-led study abroad program from the student participants can provide value and insight to the successes as well as improvements, and utilizing equitable approaches.

\section{Future Research \& Protocols}

Future research can include data collection from diverse groups, how many applicant developed and demonstrated symptoms during their study abroad experience. Effectiveness of implementation of accommodations for students that are apart of underrepresented groups that may not have access to mental health support pre-departure and abroad. A protocol formed in response to students that start to show symptoms that are different than the typical adjustments to a new culture. Students undergo what is called "culture shock" this is usually combined with homesickness and not having their strong communication and connection abroad to their support system. Research shows that "culture shock, homesickness, and stress can trigger anxiety, depression, or other mental health conditions"(Bathke \& Kim, 2016). Though some students have an awareness of their mental illness, symptoms, and what stressors can cause a flare up of symptoms, not all students have that awareness or can put words to their symptoms, or that their illness has been dormant. 
An Equitable Approach to Addressing Mental Illness Within U.S. Study Abroad Programs

\section{Conclusion}

Students that have a mental illness or experience symptoms of a mental illness can still participate in a study abroad program effectively and receive a rich cultural experience without limitations. "The results clearly demonstrate that for students to function optimally and glean positive experiences from studying abroad, psychological distress and its impact must be addressed"(Hunley, 2010). Study abroad programs can provide an equitable approach to providing accommodations to best support students experiencing symptoms of a mental illness through their study abroad experience. Through the integration of proposed methods in an equitable approach to addressing mental illness within U.S. study abroad programs, students will feel included, open, and honest with study abroad staff and faculty throughout the study abroad application and experience. Students that are informed of their rights and protections can actively engage in their own care, advocate for accommodations needed pre-departure and abroad as well as be honest and direct with the faculty leading the experience. Study abroad programs have an ethical obligation to address mental illness in an equitable and inclusive manner to best support students throughout the study abroad application and study abroad experience. 
An Equitable Approach to Addressing Mental Illness Within U.S. Study Abroad Programs

\section{References}

American College Health Association (2015). “American College Health Association-National College Health Assessment II: Reference Group Executive Summary Spring 2015.” Hanover, MD: American College Health Association. Retrieved from http://www.achancha.org/reports_ACHA-NCHAII.html American College Health Association. (2016). American College Health Association-National College Health Assessment II: Reference group executive summary spring 2016. Hanover, MD: American College Health Association

Bathke, A., \& Kim, R. (2016). Keep Calm and Go Abroad: The Effect of Learning Abroad on Student Mental Health. Frontiers: The Interdisciplinary Journal of Study Abroad, 27, 1-16.

Retrieved from

http://search.ebscohost.com/login.aspx?direct=true \&db=eric\&AN=EJ1099474\&site=ehost-live Charles C. Morse, Janet Dee Spoltore \& Paul Galvinhill (2017) College/University Counseling Centers Supporting Study Away: Challenges and Opportunities, Journal of College Student Psychotherapy, 31:4, 325-335, DOI: $\underline{\text { 10.1080/87568225.2017.1313690 }}$

Hunley, H. (2010). Students' functioning while studying abroad: The impact of psychological distress and loneliness. International Journal of Intercultural Relations, 34(4), 386-392.

King, M., Dinos, S., Shaw, J., Watson, R., Stevens, S., \& Passetti, F. et al. (2007). The Stigma Scale: development of a standardised measure of the stigma of mental illness. British Journal Of Psychiatry, 190(03), 248-254. doi: 10.1192/bjp.bp.106.024638 10(07). 
An Equitable Approach to Addressing Mental Illness Within U.S. Study Abroad Programs

Paras, A., Carignan, M., Brenner, A., Hardy, J., Malmgren, J., \& Rathburn, M. (2019).

Understanding How Program Factors Influence Intercultural Learning in Study Abroad: The Benefits of Mixed-Method Analysis. Frontiers: The Interdisciplinary Journal of Study Abroad, $31(1), 22-45$.

Portland State Office of International Affairs: Education Abroad | Welcome. (2019). Retrieved from https://www.pdx.edu/ed-abroad/

P. Prince, J. (2019). ADDRESSING MENTAL HEALTH ISSUES AFFECTING EDUCATION ABROAD PARTICIPANTS. [online] Eap.ucop.edu. Available at:

http://eap.ucop.edu/Documents/Health/Best\%20Practices\%20Mental\%20Health.pdf [Accessed 9 Apr. 2019].

Savicki, V., \& Brewer, Elizabeth. (2015). Assessing study abroad: Theory, tools, and practice (First ed.). Sterling, Virginia: Stylus Publishing, LLC.

Soe Yoon Choi, Maria K. Venetis, Kathryn Greene, Kate MagsamenConrad, Maria G. Checton \& Smita C. Banerjee (2016) Planning a Stigmatized Nonvisible Illness Disclosure: Applying the Disclosure Decision-Making Model, The Journal of Psychology, 150:8, 1004-1025

Whitlock, J., D. Charney, A. and E. Green, M. (2012). FEDERAL DISABILITY LAWS: DO THEY TRANSLATE TO STUDY ABROAD PROGRAMS?. NACUANOTE, [online] 